\title{
Correction \\ Correction: van Haastrecht et al. A Shared Cyber Threat Intelligence Solution for SMEs. Electronics 2021, 10, 2913
}

\author{
Max van Haastrecht ${ }^{1, *} \mathbb{0}$, Guy Golpur ${ }^{2}$, Gilad Tzismadia ${ }^{2}$, Rolan Kab ${ }^{2}\left(\mathbb{0}\right.$, Cristian Priboi $^{3}$, Dumitru David ${ }^{3}$, \\ Adrian Răcătăian ${ }^{3}$, Louis Baumgartner ${ }^{4}$, Samuel Fricker ${ }^{4,5}$, Jose Francisco Ruiz ${ }^{6}$, Esteban Armas ${ }^{6}$, \\ Matthieu Brinkhuis ${ }^{7}$ (D) and Marco Spruit ${ }^{1,7,8}$
}

check for

updates

Citation: van Haastrecht, M.; Golpur,

G.; Tzismadia, G.; Kab, R.; Priboi, C.;

David, D.; Răcătăian, A.;

Baumgartner, L.; Fricker, S.; Ruiz, J.F.; et al. Correction: van Haastrecht et al. A Shared Cyber Threat Intelligence Solution for SMEs. Electronics 2021, 10, 2913. Electronics 2022, 11, 349.

https://doi.org/10.3390/

electronics11030349

Received: 17 January 2022

Accepted: 19 January 2022

Published: 24 January 2022

Publisher's Note: MDPI stays neutral with regard to jurisdictional claims in published maps and institutional affiliations.

Copyright: (C) 2022 by the authors. Licensee MDPI, Basel, Switzerland. This article is an open access article distributed under the terms and conditions of the Creative Commons Attribution (CC BY) license (https:// creativecommons.org/licenses/by/ $4.0 /)$.
1 Leiden Institute of Advanced Computer Science (LIACS), Leiden University, Niels Bohrweg 1, 2333 CA Leiden, The Netherlands; m.r.spruit@lumc.nl

2 KPMG Somekh Chaikin, KPMG Millenium Tower 17 Ha'arba'a Street, Tel Aviv 6473921, Israel; ggolpur@kpmg.com (G.G.); gtzismadia@kpmg.com (G.T.); rkab@kpmg.com (R.K.)

3 CERT-RO, Italiană Street 22, 030167 Bucharest, Romania; cristian.priboi@cert.ro (C.P.); dumitru.david@cert.ro (D.D.); adrian.racataian@cert.ro (A.R.)

4 Institute for Interactive Technologies (IIT), University of Applied Sciences and Arts Northwestern Switzerland (FHNW), Bahnhofstrasse 6, 5210 Windisch, Switzerland; louis.baumgartner@fhnw.ch (L.B.); samuel.fricker@fhnw.ch (S.F.)

5 SERL-Sweden, Campus Gräsvik, Blekinge Institute of Technology, 37179 Karlskrona, Sweden

6 Atos SA, Calle Albarracin 25, 28037 Madrid, Spain; josemistra@gmail.com (J.F.R.); esteban.armas.external@atos.net (E.A.)

7 Department of Information and Computing Sciences, Utrecht University, Princetonplein 5, 3584 CC Utrecht, The Netherlands; m.j.s.brinkhuis@uu.nl

8 Department of Public Health and Primary Care, Leiden University Medical Center (LUMC), Albinusdreef 2, 2333 ZA Leiden, The Netherlands

* Correspondence: m.a.n.van.haastrecht@liacs.leidenuniv.nl

\section{Addition of Authors}

The authors wish to make the following corrections to this paper [1].

Louis Baumgartner, Samuel Fricker, Jose Francisco Ruiz, and Esteban Armas were not included as authors in the original publication. The corrected Author Contributions Statement appears here. The authors confirm that the scientific conclusions are unaffected. The original publication has also been updated.

Author Contributions: Conceptualisation, M.v.H., R.K., C.P., S.F., J.F.R., M.B. and M.S.; methodology, M.v.H., M.B. and M.S.; software, M.v.H., L.B., J.F.R. and E.A.; validation, M.v.H., M.B. and M.S.; formal analysis, M.v.H.; data curation, M.v.H.; writing—original draft preparation, M.v.H., G.G., G.T., R.K., C.P., D.D. and A.R.; writing-review and editing, M.v.H., G.G., G.T., R.K., C.P., D.D., A.R., M.B. and M.S.; visualisation, M.v.H., L.B., J.F.R. and E.A.; project administration, M.v.H. All authors have read and agreed to the published version of the manuscript.

\section{Reference}

1. van Haastrecht, M.; Golpur, G.; Tzismadia, G.; Kab, R.; Priboi, C.; David, D.; Răcătăian, A.; Baumgartner, L.; Fricker, S.; Ruiz, J.F.; et al. A Shared Cyber Threat Intelligence Solution for SMEs. Electronics 2021, 10, 2913. [CrossRef] 